HISTORY OF MEDICINE

\title{
Salmonella: a continuing problem
}

A Hardy

Postgrad Med J 2004;80:541-545. doi: 10.1136/pgmj.2003.016584

Salmonella was the archetypal food poisoning organism of the 20th century. It achieved a high public profile following the salmonella-in-eggs crisis of 1988-89, but by then had been the subject of public health concern and scientific interest for over a century. Early associated with animal foods, the advent of phage typing in the 1940s began to reveal the complexity of its environmental associations. This paper explores the story of salmonella as a continuing problem in epidemiology, microbiology and public health, in the food chain, and in the kitchen.

Correspondence to:

Dr A Hardy, Wellcome

Trust Centre for the History of Medicine at UCL, Euston House, 24 Eversholt Street, London NW1 1AD, UK; a.hardy@ucl.ac.uk

Submitted

31 October 2003

Accepted

17 December 2003
S almonellas were the foremost of the food poisoning organisms for almost the whole of the 20th century. Coming to public prominence only in the last decades of that century, the salmonellas had none the less been a cause of public health concern for over a 100 years. Although stomach disorders and food items had been causally linked probably since human history began, the discovery of the first food poisoning organisms between 1888 and 1900 forged a new understanding of food related illness. Before the 1880s, food poisoning had been known as ptomaine poisoning, and ascribed to chemical changes in decomposing foodstuffs. ${ }^{1}$ From the early 1880s, however, it came to be understood as being due to bacterial infection, causally associated with the consumption of animal foods, especially pork, beef and milk, and with "manipulated" foodstuffs such as meat pies, cream cakes, and ice cream. ${ }^{2}$ In 1900, the salmonellas represented a novel and exciting avenue for medical exploration and elucidation of the causes of human illness. They became the subject of worldwide attention from microbiologists, epidemiologists, and public health administrations. By the 21st century, however, despite a vastly greater understanding of their structure, relationships and natural history, they remain what they were in 1900: an unresolved conundrum in microbiology, epidemiology, and public health.

\section{A PROBLEM OF PREVALENCE}

The incidence and prevalence of food poisoning in England and Wales only began to become apparent after the condition was made notifiable in 1939. From an initial total of some 100 recorded cases a year, the figures climbed rapidly into the 1000s by 1949, and to over 6000 a year by 1954. Contemporaries debated the reality of this increase, but in 1956 Sir William Savage (1872-1961), the leading British authority on food poisoning, concluded that there had, indeed, been an enormous increase in prevalence. ${ }^{3}$ Savage's judgment remains debatable, despite the fact that his own engagement with the subject dated from circa 1905. Until 1939, the reporting of food poisoning incidents remained highly random, and sporadic cases were rarely recorded at all.

Awareness of food poisoning as a public health problem emerged with the new bacteriology in the 1880s. Between 1880 and 1890, the Medical Department of the Local Government Board (predecessor to the Ministry of Health) collected information on 14 incidents ranging from family episodes to guests at a wedding. ${ }^{4}$ Retrospective diagnosis (admittedly a dodgy exercise) suggests 10 of these were due to salmonella. In 1913, Savage was able to list 79 outbreaks occurring in Britain and Ireland between 1878 and $1911 .^{5}$ At the same time other indicators suggest the widespread prevalence of foodborne disease. The death rate from typhoid (Salmonella typhi), for example, which had been falling since 1875 after the achievement of improved domestic water supplies, reached a plateau in the late 1880s, to begin falling again after 1900, after the discovery of human carriers, and of the hazards presented by shellfish. ${ }^{6}$ At the same time, gastroenteritis remained an endemic problem, especially in cities. In the Victorian period, especially during the summer months, local dispensaries were often over-run by the demand for diarrhoea medicines, and many authorities testified to the existence of epidemic diarrhoea as a widespread family problem, often introduced by the adults of the household. ${ }^{7}$

Most such illness escaped statistical collection or attention from the health authorities. It was noted in 1934 that the frequent occurrence of single, sporadic cases of salmonellosis was not widely recognised. ${ }^{8}$ Although the Chief Medical Officer and others suggested that increased communal feeding in wartime lay behind the rising incidence of food poisoning after 1940, the notification data revealed sporadic cases (as opposed to outbreaks) to be a significant feature in that incidence: by 1949-54 they accounted for well over half all reported incidents, increasingly regularly year on year. ${ }^{3}$ Today, sporadic cases make up the great bulk of salmonella incidents. A greater, and growing, willingness of patients to call in the doctor once free general practitioner care became available after 1948 may partly account for this pattern, but failure to call the doctor continued, and continues, to pose a problem in assessing the real prevalence of salmonellosis. In 1966, it was suggested that the average adult experienced two attacks of diarrhoea and vomiting a year without seeking medical attention. ${ }^{9}$ In 1996 it was recorded that 
only one in 26 people suffering an acute episode of gastroenteritis consult their general practitioner. ${ }^{10}$

Within this spectrum of food related illness, salmonella played the major part. Already in 1907, Savage reported that the great majority of episodes of food poisoning were due to Salmonella enteritidis and its relations. ${ }^{11}$ Over the next 50 years, various authorities repeatedly endorsed this judgment. In a series of 100 food poisoning incidents analysed by Savage and Philip Bruce White (1891-1949) between 1921 and 1923, $70 \%$ were stated to be due to salmonella. ${ }^{12}$ In 1930, the figure of nearly $90 \%$ was being quoted, and in 1956 Savage ascribed 91.4\% of food poisoning incidents recorded between 1941 and 1948 as due to salmonella. ${ }^{3}$ In 1987 the figure of $90 \%$ was still being authoritatively quoted, ${ }^{13}$ but in 1981 campylobacter had been identified, and by 1997 had overtaken salmonella as the commonest food infection in Britain. ${ }^{14}$ Clostridium welchii and staphylococcal food poisoning have caused concern from time to time, but neither has approached salmonellosis in scale of incidence.

\section{A PROBLEM IN PUBLIC HEALTH AND EPIDEMIOLOGY}

Active recognition of salmonellosis, or indeed of food poisoning in general, as a problem was slow to emerge in Britain's public health community. The central Medical Department did regard it as a problem from the 1880s, and it was given an individual entry in the Chief Medical Officer's annual reports from 1920. The interwar Ministry of Health encouraged the local investigation of food poisoning outbreaks, without much success. Local medical officers of health had more pressing concerns: as a cause of morbidity, economic loss and limited preventable mortality, food poisoning was a worry, but was a relatively very minor cause of death, and so attracted little practical attention from local health authorities in the years to 1940. Savage and Bruce White noted in 1925 that accounts of food poisoning outbreaks were hardly ever published, and all too frequently were either investigated superficially or not at all. Although most medical officers of health complied with their own requests for information, there were those who showed little interest in the research or the epidemiological problem of food poisoning, confining their attention to the administrative problem presented by an outbreak. Once it was over, it ceased to be a problem, and was of no further significance. ${ }^{12}$ Again, in 1937, the Kent County Pathologist noted that few outbreaks were completely investigated, and deplored the failure to publish negative findings: "a clearer understanding of the factors involved in bacterial food poisoning will more easily be acquired only by a comparison and correlation of all findings, whether these be positive or negative" ${ }^{\prime 15}$

The failure of medical officers of health to inquire systematically into food poisoning was in part because it was a highly frustrating and time consuming problem to investigate. As the assistant medical officer of health for Cardiff noted in 1936, "The linking up of individual cases and the discovery of the incriminating foodstuff etc, has been and still is one of the most baffling of medical and public health problems". Above all, a satisfactory outcome necessitated close cooperation between three different public health sectors. The medical officer of health had to trace all cases, find the vehicle of infection, and stop its distribution; the bacteriologist had to confirm the diagnosis, type the organism, and if possible incriminate the suspected vehicle; and finally, the veterinarian had to assist in tracing the path of the infection and find its source. ${ }^{16}$ The control of food poisoning, it was observed in 1946, was in theory the easiest duty of the medical officers of health, in practice the most anxious. ${ }^{17}$
Concerns about food poisoning and salmonellosis did, however, exist in the public health community during the interwar period. In 1926, for example, a joint committee of the Society of Medical Officers and the Royal Sanitary Institute published Clean Food, a report which identified the core problem as a national lack of interest in the subject, and a need for popular education in this respect. The pages of the public health journals in these years reflect a continuing interest among some members of the community in problems of food poisoning and the salmonellas, but it was not until after World War II that this began to broaden, partly at least as a result of technical advances in microbiology which greatly facilitated the relating of case to cause, and partly because of the establishment of the Public Health Laboratory Service which greatly increased ease of access to diagnostic laboratory services. The apparently relentless rise in notification was another stimulus: it was claimed, for example, that food poisoning (and hence salmonellosis) had become "almost the major public health topic of the post-war years". ${ }^{18}$

\section{A PROBLEM IN MICROBIOLOGY}

From a very early date, the precise identification of the causal organism was recognised as the key to solving and preventing outbreaks of food poisoning. In the case of the salmonellas, however, this proved to be far from straightforward. Several different "meat poisoning" organisms, as they were then known, were identified in the decade following August Gaertner's recovery in 1888 of $S$ enteritidis from both the carcase of an emergency-slaughtered cow and the body of a man who died after eating her meat. Bacteriologists experienced great difficulty, however, in distinguishing between these different organisms. In 1898, however, Herbert Durham (1866-1945) demonstrated that these micro-organisms could be separated into two distinct groups by means of agglutination tests; he also noted the diagnostic value of serological examination of patients suffering from food poisoning. ${ }^{19}$ By 1900, the salmonellas had been recognised as a distinct group of organisms, with Salmonella cholerae-suis as the type. ${ }^{20}$

Yet confusion continued, partly through problems with new laboratory techniques, and partly because numerous laboratory workers across Europe and America in identifying the same bacteria blessed them with a variety of different names, the same name being also used for several different organisms. By the early 1920s, the taxonomy of salmonella was in complete confusion. Thus, for example, Salmonella typhimurium was variously known as the Mutton type, the Hatton strain, Salmonella aertrycke, Salmonella suipestifer, the Breslau type, and the Freiburg type, to name a few. ${ }^{21}$ During the 1920s microbiologists began to work towards a unified taxonomy by serological comparison of representative cultures. Significant contributions were made in this field by Philip Bruce White in London, and by Fritz Kauffmann (1899-1978) in Copenhagen, and general agreement was finally achieved under the aegis of the Salmonella Subcommittee of the International Society for Microbiology in 1933. Henceforward, the different salmonellas were classified under the Kauffmann-White scheme, and newly identified members of the genus were to be named after the place where they were first recognised. ${ }^{22}$ In the 1930s also, the international nature of the salmonella problem was recognised with the establishment of a global network of salmonella reference centres.

Meanwhile the number of salmonella types recognised internationally continued to grow. The Salmonella Subcommittee had recognised 45 types; by 1939 more than 80 were known, and by 2000, some 2200. In the 1930s, the salmonella group, typhoid apart, was generally viewed by the medical profession as being "a desert of complexity", and 
the news that the development of phage typing had led to the subdivision of typhoid into seven different types was initially viewed with alarm. ${ }^{23}$ Within a few years, Arthur Felix (18871956) and his co-worker had extended the technique of phage typing to paratyphoid B and S typhimurium, ${ }^{24}{ }^{25}$ and the laboratory detection of the salmonellas entered a new era, in which the causal organisms could be identified ever more precisely in laboratory isolations. One of the consequences of this new refinement in identification was to throw open the epidemiological investigation of salmonella incidents in the field. Where defined food poisoning outbreaks had long been the focus of interest, phage typing conferred a new significance on sporadic cases. These had once been thought to be isolated occurrences; phage typing could now reveal previously unsuspected links between scattered cases over a wide geographical area. ${ }^{26}$

Even with a clarified taxonomy, however, problems persisted for the microbiologists. The laboratory investigation of food poisoning incidents was never less than expensive and time consuming, ${ }^{15}$ and became more so in the years after 1950 as the increasing sophistication of laboratory techniques revealed more and different organisms with a part to play in food poisoning incidents apart from the salmonellas. ${ }^{27}$ Moreover, it has often proved difficult to obtain the samples necessary for elucidation of the causal organism. In the years before refrigeration, at least until World War II, diagnostic samples reaching the laboratory had often deteriorated beyond the point of being useful, and the acquisition of samples of foodstuffs suspected of being the vehicle of infection has frequently proved difficult, the foods in question having all been eaten or disposed of before investigations can begin.

Over the years, too, many microbiologists also worried over the wider question of where these bacteria came from. As Durham observed already in 1899, the identification of a given microbe was only the beginning of the knowledge requisite for its control: "we must also know its economy in nature" ${ }^{\prime 28}$ The knowledge that the salmonellas were found in food animals, notably in pigs and cattle, was there from their earliest identification, but the question remained, how did they get there? Early experiments by William Savage confirmed that they were not normal inhabitants of the animal gut. ${ }^{29}$ Nor, for many years, was it thought that human carriers played a part in the distribution of the lesser salmonellas. Although the existence of healthy human carriers of typhoid and paratyphoid had been known since the turn of the century, human excreters were thought unlikely to play a part in food poisoning episodes as late as the 1930s. ${ }^{8}$ With the greater opportunities for laboratory and epidemiological investigation brought about by notification and the wartime expansion of the public health laboratory system, this belief was gradually undermined. By 1950, evidence of the existence of symptomless human salmonella excreters was accumulating. ${ }^{30}$ By the 1980 s, it was recognised that the salmonellas are "the only food-poisoning organisms in which human beings as carriers pose potential problems as sources of outbreaks" ${ }^{13}$

The multiple sources of salmonella organisms make their detection and management extremely problematic, and the laboratory continues to play a major part in the elucidation of salmonellosis. The development of molecular epidemiology in the 1980s, ${ }^{31}$ and successive refinements in biotyping techniques and their application, have provided new and powerful tools in the search for associations between salmonella strains and their hosts. ${ }^{32}$

\section{A PROBLEM IN THE FOOD CHAIN}

Despite the early identification of food animals as sources of human infection with salmonella, the study of salmonellosis in animals was slow to develop. Savage and Bruce White drew attention to the likelihood of rats and mice providing a reservoir of infection, ${ }^{33}$ and significant contributions in determining the existence of salmonella in duck eggs, ${ }^{34}$ and in healthy pigs at slaughter, ${ }^{35}$ were made by W M Scott (1884-1941) of the Ministry of Health laboratory in the 1930s, but their "economy in nature" went otherwise unexplored. In part this was probably due to interwar problems in the veterinary profession, in Britain at least: horses had been the mainstay of veterinary practice before 1914, but the rapid decline in horse populations after 1920 brought financial uncertainty and a period of professional readjustment to a changing animal clientele. Moreover, there were tensions between leaders of the profession who wished to encourage research, and the great majority, who insisted that practice was a far more important activity.

In February 1940, however, microbiologists, epidemiologists, and veterinarians were brought together to discuss salmonella infections at the Royal Society of Medicine, ${ }^{35}$ and the general ignorance of reservoirs of salmonella infection was noted, as being "largely a problem for workers in the veterinary field". ${ }^{36}$ Possibly as a result, but perhaps also because of the rising recorded incidence of food poisoning, the pages of the Veterinary Record were by the later 1940s bearing testimony to an upsurge of veterinary interest in salmonellosis. Early researches into the incidence of salmonella infection in cattle suggested that it existed only as a localised problem, with marked regional variations in incidence. ${ }^{37}$

The relaxation of wartime rationing restrictions in 195354 , was followed by a sharp rise in the numbers of animals coming into abattoirs for slaughter, a rise in meat consumption (and a striking increase in human salmonella infection in 1955), and within a few years by a major change in farming patterns. Intensive farming, initially of pigs and poultry, later of beef calves, became the order of the day. Already in 1954 it had been noted that the amount of time spent by animals in lairages before slaughter increased their vulnerability to salmonella infection, and by 1957, veterinarians were warning that the new farming methods also facilitated the rapid spread of infection, and might lead ultimately to increased bacterial virulence; the increase in salmonella food poisoning incidence in humans in Britain was observed to be concurrent with a similar increase in food-producing animals. ${ }^{38}$ Nor were pigs and cattle alone implicated: by 1959 salmonella infection rates in hens' eggs, a phenomenon unrecorded before the war, had reached "alarming" proportions. ${ }^{39}$

Two other disturbing features of the new postwar economy raised further anxieties around animal salmonellosis. In 1952, the value of antibiotic feeding supplements in rearing unthrifty pigs had been noted in both Britain and the United States. ${ }^{40}$ Within a decade, antibiotic supplements had come into common use, despite urgings for caution from, among others, the president of the Royal College of Veterinary Surgeons. By the mid-1960s, there was good evidence that drug resistant strains of $S$ typhimurium were being spread across the country by calves. ${ }^{41}$ It was only the beginning of a problem that had, by 2000, also spread into human salmonella infections. In the meanwhile, it had also become clear that imported animal feeding stuffs-another result of the new postwar global trade phenomenon-often contained significant levels of salmonella contamination, and could be correlated with the appearance of many new salmonella serotypes in laboratory isolations. ${ }^{42}$

The new ecology of salmonellosis on the farm had complex roots, but was increasingly seen to be associated with the incidence of salmonella infection in humans. In 1975, the Agriculture Section of the British Association for the 
Advancement of Science (BAAS) drew attention to the zoonoses as a growing danger to the health both of the British people and of the livestock on which they depended for food. A BAAS study group subsequently selected the salmonellas for further investigation, as being the zoonosis currently of most immediate public significance, and in 1978 the organisation published its expert survey, Salmonella. The Food Poisoner. Intended as a popularly accessible work, the report surveyed the problems relating to salmonellosis in animals and salmonella food poisoning in man. At the press conference to launch the review, the BAAS spokesman observed succinctly that "Fifty percent of outbreaks of food poisoning in humans are attributable to poultry, $20 \%$ to meat products, mainly pork, and $20 \%$ to milk and cream products". ${ }^{43}$ The connection between human and animal salmonellosis could not have been more clearly made, while the report itself bore eloquent testimony to the problems salmonella presented to the livestock industry.

The hope of the BAAS was that the 1978 report would be read not just by those directly concerned with human and animal salmonellosis, but also by caterers, food manufacturers and distributors, and members of the general public, especially housewives. Through the 1980s, however, the problem of salmonellosis continued to escalate, and there was little to suggest that such publicity as the report generated had the desired educational effect. In 1985 the Chief Medical Officer reported that "All stages in the chain that bring salmonella to man-farming methods, animal husbandry and transport, slaughter, food processing, retail and consumer practices-require attention in order to decrease or eliminate the salmonella load to which we are exposed". ${ }^{44}$ Food scares proved a more effective educational vehicle, at least temporarily. In December 1987, the great egg scandal broke following perhaps careless words by a junior agriculture minister, Edwina Currie (b 1942), to the effect that most British egg production was infected with salmonella. Generally interpreted by press and public as meaning that most eggs were infected, the result was a $60 \%$ slump in egg sales within 10 days. ${ }^{45}$

As a result of the 1988-89 egg scare, the government appointed the Advisory Committee on the Microbiological Safety of Foods, which produced two reports on salmonella in eggs, in 1993 and 2001, both of which carried curious echoes of Durham's admonition of a 100 years earlier, and of the interwar researches into potential salmonella reservoirs in nature by Savage and Bruce White. Thus the 1993 report noted that "the maintenance of salmonellas in the environment is by complex pathways, and rodents and wild birds may act as important reservoirs of infection", ${ }^{46}$ while the second report detailed the environmental measures to be taken in the interest of "biosecurity and farm hygiene" ${ }^{47}$

\section{A PROBLEM IN THE KITCHEN}

In the progression of salmonella organisms from field to fork, they are almost invariably processed through a kitchen (except in raw milk); and in this progression, the "ghastly kitchen" of the abattoir has proved an important staging post. Already in the 1880 s there was growing concern about the human consumption of the meat of diseased animals. Much of this was associated with bovine tuberculosis, ${ }^{48}$ but knowledge of the transmission of the salmonellas through meat also contributed. Two points of anxiety emerged: the entry of diseased meat into the food chain, and abattoir practices that resulted in the contamination of healthy meat with faeces and gut contents. Throughout the first half of the 20th century the problem of slaughterhouse regulation and supervision was consistently to the fore: not an easy task in an industry dominated by many small independent operators. Centralised supervision during the war was greeted with relief, but after the war hopes for its continuation were disappointed. ${ }^{49} \mathrm{New}$ postwar regulations did little to solve the problem: in 1970 it was suggested that some $24 \%$ of cattle carcases examined were infected with salmonella. ${ }^{50}$ Britain's entry into the European Community in 1974 brought fresh reflections on standards of meat and poultry meat hygiene, but in the mid-1980s it was recognised that both the meat industry and those involved in its regulation still needed to be "brought into the 20th century". ${ }^{51}$ Slaughterhouse and butchery practices remain problematic, and through the 1990s evidence continued to be produced to show that slaughterhouse practice plays a significant part in the propagation of salmonella infections..$^{52}$

Given sources of infection in raw foods, inadequate cooking, and faulty domestic and personal hygiene have long been recognised as factors of cardinal importance in the production of food poisoning. Of the hams which occasioned an epidemic at Welbeck in 1880, for instance, the investigator noted explicitly that insufficient cooking was a common fault with hams cooked for sale. ${ }^{7}$ Durham's investigation of an outbreak of veal pie poisoning in Oldham in July 1898, revealed that these commercially baked pies were cooked for just 20 minutes at $450^{\circ}$ to $400^{\circ} \mathrm{F}$, while his information was that in domestic cookery even a single small raised pie was given at least 50 minutes. ${ }^{28}$ Both the medical officer of health for Oldham and William Savage castigated the widespread habit of buying prepared and partially prepared foods for home consumption as productive of food poisoning. Nor was home cooking necessarily safer: many working people still cooked over open fires, and habitually "warmed" their bacon and sausages rather than cooking them through; the consumption of raw sausages (with unfortunate results) was not unknown. Both cooking and washing facilities, let alone their usage when available, remained problematic in both commercial and domestic premises into the $21 \mathrm{st}$ century.

If the focus was initially on the preparation and cooking of animal foods, it was not long before concerns about personal cleanliness began to surface as a corollary of the new bacteriological knowledge. By the interwar period, British medical officers of health were recording a general disregard for food hygiene, and urging the necessity for "propaganda, publicity and teaching". ${ }^{53}$ Personal cleanliness among food handlers came in for particular criticism: "It is unusual to find these people clean, their hands and nails are dirty, their clothes are dirty, and their habits are uncleanly". ${ }^{54}$ Shortages of soap and washing powder during World War II may have aggravated the problem; there was a widespread postwar perception that food hygiene standards had further deteriorated during the war. ${ }^{55}$ Even before the war, an effort had been made, in the Food and Drugs Act 1936, to improve food handling practices through regulation (as for the provision of washbasins in commercial premises) and education. In 1946, however, a series of food poisoning outbreaks made food hygiene a national concern, and the issue was taken up by a range of activists, from the Ministry of Food, the Medical Research Council and the Central Council for Health Education to the Royal Sanitary Institute, the Tourist Board, the Women's Institutes, and the popular press. The 1954 Food and Drugs Act, which greatly strengthened the law relating to food hygiene, was immediately absorbed into the consolidatory Food and Drugs Act 1955; similar legislation was passed for Scotland in 1956. With this legislation, general interest in the subject waned. ${ }^{56}$ It was only with the salmonella-in-eggs crisis of 1988-89 that food poisoning reemerged as a popular and political issue.

Throughout the 1990s, public interest in food poisoning issues remained high. The emergence of virulent Escherichia coli 0157, signalled in Britain by the 1996 outbreak associated 
with Barr's butchers in Lanarkshire, sharpened that concern As Hugh Pennington notes in that context, hand washing remains a continual theme in any account of food poisoning. ${ }^{57}$ Salmonella, meanwhile, retained its prominent profile, remaining for most people the archetypal food poisoning organism. Investigations into both outbreaks and sporadic cases of human salmonella infection continued to emphasise the importance of kitchen hygiene, whether in the catering trades or in the home. And, it was beginning to be intimated, the two types of occurrence might be more intimately linked than previously supposed. The authors of one recent investigation, for example, warned explicitly against "assuming that the main causes of sporadic salmonellosis lie within the domestic kitchen". Apparent sporadic cases may rather represent unrecognised community-wide outbreaks which, if the organism concerned is common and the level of contamination low, may go undetected, appearing only as sporadic cases in the routine statistics. ${ }^{58}$ Thus individual failures in kitchen hygiene still link back into the food chain, and into the wider circle of the ecology of salmonella.

\section{CONCLUSION}

Salmonellosis is a problem that affects all modern societies in varying degrees. It is not a new problem, and persistent themes run through its history: the detection of the precise causal organisms, their natural history, the ways in which they are communicated to humans, and the means for preventing this, have been the subject of medical concern for over a century. Despite astonishing advances in scientific techniques and greatly improved knowledge, modern societies remain as far as ever from resolving this particular problem of human health.

\section{REFERENCES}

1 Dewberry ED. Food poisoning: food-borne infection and intoxication. London: Leonard Hill, 1959.

2 Savage W. Food and the public health. London: Cassell \& Co, 1919

3 Savage W. Problem of food poisoning. BMJ 1956;ii:317-23.

4 British Parliamentary Papers, 1890-91:34; appendix 21: 245-58.

5 Savage W. On bacterial food poisoning and food infections, Reports on public health and medical subjects, NS No 77, 1918.

6 Greenwood M. Epidemics and crowd diseases. London: Williams and Norgate, 1935.

7 Hardy A. Food, hygiene and the laboratory: a short history of food-poisoning in Britain 1880-1960. Social History of Medicine 1999;12:293-311.

8 Smith J. Sporadic salmonella infections: a new salmonella type. Journal of Hygiene 1934;34:351-60.

9 Anonymous. Food poisoning [editorial]. Public Health 1966-67:81:49.

10 Palmer S, Houston H, Lervy B, et al. Problems in the diagnosis of foodborne infection in general practice. Epidemiology and Infection 1996;117:479-84.

11 British Parliamentary Papers, 1909:28; appendix B no 5.

12 Savage W, Bruce White P. An investigation of the salmonella group, with special reference to food poisoning. Medical Research Council Special Report Series, No 91, 1925.

13 Cruickshank JG, Humphrey TJ. Special article: the carrier food-handler and non-typhoid salmonellosis. Epidemiology and Infection 1987;98:223-30.

14 Chief Medical Officer. On the state of the public health. London: HMSO 1997:21.

15 Jones ER. Food poisoning-its epidemiology and bacteriology. Journal of State Medicine 1937;45:404-16.

16 Anderson CW. Food poisoning. Public Health 1936;49:132-4.

17 Anonymous. Food poisoning [editorial]. Medical Officer 1946;76:1

18 Anonymous. Food poisoning [editorial]. Public Health 1949;62:222.

19 Durham HE. The present knowledge of outbreaks due to meat poisoning. BMJ 1898;ii:1797-801.

20 Lignières MJ. Contribution a l'étude et à la classification sépticemies hémorragiques les "pasteurelloses". Annales Institut Pasteur 1901:15:734-6.

21 Bruce White P. The salmonella group. A system of bacteriology in relation to medicine. Medical Research Council. London: HMSO, 1929;14:86-158.
22 Salmonella Subcommittee. The genus salmonella Lignières, 1900. Journal of Hygiene 1934;34:333-50.

23 Anonymous. Serological diagnosis of typhoid [annotation]. BM 1938;ii: 2111

24 Felix A, Callow BR. Typing of paratyphoid B bacilli by means of $\mathrm{Vi}$ bacteriophage. BMJ 1943;2:127-30.

25 Callow BR. A new phage-typing scheme for Salmonella typhi-murium. Journal of Hygiene 1959;57:356-9.

26 Anderson ES. Special methods used in the laboratory. Royal Society of Health Journal 1960;80:260-7.

27 Turner GC, Anderson RD, Ashton Cl. Investigating gastro-enteritis: the Merseyside experience 1983-1987. Public Health 1988;102:419-30.

28 Durham HE. On infections by unsound meat, more especially with regard to the bacillus enteritidis (Gartner). Transactions of the Pathological Society 1899;50:262-8.

29 British Parliamentary Papers, 1908:30; appendix B no 5.

30 Grant J. Human salmonellosis. Medical Officer 1951;86:117-19.

31 Maslow JN, Mulligan ME, Arbeit RD, et al. Molecular epidemiology: application of contemporary techniques to the typing of microorganisms. Clinical Infectious Diseases 1993;17:153-62.

32 Old DC, Chisholm SA, Crichton PB, et al. Grouping of Salmonella enterica serotype Montevideo strains by ribotyping and IS200 profiling. Epidemiology and Infection 2000;124:375-82.

33 Savage W, Bruce White P. Rats and salmonella group bacilli. Journal of Hygiene 1922-23, 21:258-61.

34 Scott WM. Food poisoning due to eggs. BMJ 1930;ii:56-8.

35 Anonymous. On salmonella infections [discussion]. Proceedings of the Royal Society of Medicine 1939-40, 33:357-70.

36 Anonymous. Salmonella infections [editorial]. Veterinary Record 1940;52:557.

37 Field HI. Salmonella infection in cattle. Veterinary Record 1949;61:109-13.

38 Buxton A. Public health aspects of salmonellosis. Veterinary Record 1957;69:105-9.

39 Anonymous. Food infection hazards [editorial]. Medical Officer 1959;102:259

40 Worden AN, Bunyan J. The administration of a procaine penicillin feeding supplement to "runt" pigs. Veterinary Record 1952;64:647-51.

41 Anderson ES, Lewis MJ. Drug resistance and its transfer in salmonella typhimurium. Nature 1965;206:579-83.

42 Public Health Laboratory Service. Salmonella organisms in animal feeding stuffs and fertilisers. PHLS report. Monthly Bulletin of the Ministry of Health 1959; 18:26-35.

43 Anonymous. Salmonellosis increases in humans and livestock [news and reports]. Veterinary Record 1978;102:271-2.

44 Chief Medical Officer. On the state of the public health. London: HMSO 1985.

45 Webster P, Young J. Clarke in bid to defuse row over egg risk. The Times 6 December 1988/Staff reporters. Hens face slaughter as egg sales drop. The Times 10 December 1988.

46 Advisory Committee on the Microbiological Safety of Foods. Report on salmonella in eggs. London: HMSO, 1993.

47 Advisory Committee on the Microbiological Safety of Foods. Second report on salmonella in eggs. London: HMSO, 2001

48 Waddington K. "Unfit for human consumption": tuberculosis and the problem of infected meat in late Victorian Britain. Bulletin of the History of Medicine 2003;77:636-61.

49 Bywater HE. Public and private slaughter-houses in England and Wales. Veterinary Record 1948;60:219-20.

50 McCaughey WJ, Pearson JKL, McClelland TG. A knackery survey of salmonellae in cattle. Veterinary Record 1971;89:479-82.

51 Morris JE. Meat and meat hygiene, towards the twenty first century, hygiene requirements and inspection. Royal Society of Health Journal 1985; 105: 198-9

52 Hendrickx M, Vandekerchove D, Herman L, et al. Routes for salmonella contamination of poultry meat: epidemiological study from hatchery to slaughterhouse. Epidemiology and Infection 2002;129:253-65.

53 Porter C. The public and food hygiene. Journal of the Sanitary Institute 192526, 41:427-32.

$54 \mathrm{McClure}$ WStC. The importance of cleanliness in the preparation and distribution of food. Journal of the Sanitary Institute 1923-24;44:316-17.

55 Anonymous. Infected foods [notes and comments]. Medical Officer 1947:78:154

56 Barr RI. Food hygiene-the arousal of public awareness. Royal Society of Health Journal 1978;98:55-7.

57 Pennington TH. When food kills: BSE, E coli and disaster science. Oxford: Oxford University Press, 2003.

58 Parry SM, Palmer SR, Slader J, et al. Risk factors for salmonella food poisoning in the domestic kitchen-a case control study. Epidemiology and Infection 2002;129:277-85. 